\title{
Correlational Study between Dream Content and Somatic Symptoms: When the Dream Alerts on an Incubated Symptom
}

\section{Mbangmou Romuald Stone ${ }^{1 *}$ and Nguimfack Léonard ${ }^{2}$}

${ }^{1}$ PhD Student, Department of Psychology, University of Yaounde 1, Cameroon ${ }^{2}$ Associate professor, department of psychology, University of Yaounde 1, Cameroon *Corresponding Author: Mbangmou Romuald Stone, PhD Student, Department of Psychology, University of Yaounde 1, Cameroon.
Received: February 26, 2020

Published: April 16, 2020

(C) All rights are reserved by Mbangmou

Romuald Stone and Nguimfack Léonard.

\begin{abstract}
This study questions the function of the dream in general, and the relation between the manifest content of the dream and the physical symptoms that the dreamer experiences during the period of illness. Based on studies on the relationship between manifest dream content and the onset of inflammatory somatic symptoms in dreamers, initiated by Vaschide and Pieron since the 1900s, and the observation of several clinical cases received during the last five years, we set ourselves the objective in this work of quantifying the link between the intensity of the somatic symptoms felt by the patient, and the frequency of appearance of dreams whose manifest content solicits the dysfunctional physiological system. In other words, it is a question of checking statistically if there is a relationship between the dream that the patient has during his nights, and, the place of expression and the intensity of the symptoms he feels in his body. The synthesis activation theory allowed us to formulate the hypotheses and to interpret the results. It turns out in the light of the results of this study that the physical symptoms experienced by the patient can significantly modify the manifest content of their dreams.
\end{abstract}

Keywords: Somatic Symptoms; Dream Manifest Content; Correlational Analysis; Dream Function; Synthesis Activation Theory

\section{Introduction}

The dream is undoubtedly the first function of the organism which intrigued primates in general, and humans in particular [1]. Unlike the other mental functions which have been explored by the sciences for centuries, the dream phenomenon waited until the first year of the 20th century to see the appearance of a first scientific theory concerning it. Since then, a few rare scientific theories have been proposed. Jouvet [2] and Nielsen [3] said during conferences that the dream is the least explored mental function today and adds that less than $1 \%$ of researchers are interested in it. But, as Gay points out [4: P.115], "the dream escapes all restrictive theorization". Montangero [5] states that the most widespread ideas on the dream, namely those of psychoanalysis and neuroscience, are not convincing. In Freudian psychoanalytic theory, dreams are viewed both as the hallucinatory expression of the return of repressed representations in the unconscious system and as neurotic symptoms.

Their main function would be to keep sleep, in a way inhibiting the psychological conflicts and physical tensions of the sleeper. For neurobiology and psychology, the main function of dreams is to maintain and perfect cognitive and affective functions [6,7]. Far from a positioning debate between these different theories, it is a question in this research of questioning the symptomatological expression of dreams, not in relation to psychic disorders as did psychoanalysis, but in relation to physical disorders or diseases. The interest in the relationship between physical symptoms and dream content does not start with this research. Since then, "Doctors of Greek Antiquity had already recognized that the first symptoms of a physical illness could be discerned in the dreams of the patient before the appearance of the external diagnostic criteria" [8, P.10]; Starting from the psychophysiological position of the synthesis activation theory of Hobson and McCarley which stipulates that the dream results from the synthesis and interpretation made by the cortex of the neural signals that the activity of the cerebral cortex triggers [6,7], we set ourselves the objective of quantitatively evaluating the link between the intensity of the somatic symptoms felt by the patient, and the frequency of the appearance of dreams, the manifest content of which solicits the dysfunctional physiological system. In other words, it is a question of verifying methodically whether there is a statistically significant relationship between the dream that the patient has during his nights, and, the place of expression and the intensity of the symptoms he feels in his body. Starting from this synthesis activation theory, we postulate that the quality of painful or disruptive bodily sensations received by the hypothalamus and relayed in the PGO system which is the dream producing system, would impact on the manifest content of dream of the patient. In other words, the symptoms felt by the patient would be expressed at least in part, in the unfolding of the events in their dream.

Two systems have been selected for highlighting. These are the digestive system and the respiratory system, which each constitute the independent variable of each of the first two following research hypotheses concerning frequencies: patients with respiratory problems would have more dreams in which the respiratory system is stressed than those who do not suffer from it (Hr1); patients suffering from digestive problems would have more dreams 
in which the digestive system is stressed than those who do not (Hr2). And the third hypothesis which relates to the link of correlation and dependence between the variable physical symptoms felt and the variable dreamlike manifest content is as follows: there is a link between the somatic symptoms felt by the patient and the manifest content of his dreams (hr3).

\section{The main theories and presumed functions of dreams}

Among the most well-known scientific dream theories, we can cite psychoanalytic theories.

\section{Psychoanalytic theories}

The dream at Freud's

Most of Freud's work revolves around dreams. At the conference he held at Clark University in 1904, he said: "I admit to having wondered if, instead of giving you a broad overview of psychoanalysis, I would not have done better to explain to you in detail the interpretation of dreams" [9: P.28]. He adds that one can only become a psychoanalyst by studying one's dreams. For him, dream production is comparable to that of mental illness and that of perfect health, and the dream is the "royal way that leads to the unconscious", and at the same time the guardian of sleep. Freud distinguishes the "manifest content" of the dream from its "latent content". The manifest content is "the explicit story that is remembered upon awakening" and the latent content is that "which appears during the analysis" $[9,10]$. He asserts that "the" manifest content "of the dream can therefore be considered as the disguised realization of repressed desires" [9: P.31]. The disguise of reality goes through a four-step process which he calls the "dream job". For Freud [10], repressed desires pass from the preconscious to the unconscious through the "regressing" movement. Depending on the energy charge that accompanies the repressed (especially when it is considerable), it will return during sleep, when the censors are lowered or weakened by the reduction of consciousness, after having undergone condensation, displacement, a symbolic figuration. All this distorts the representation, which can therefore access the psychic of the neurotic during his sleep in a new form. This movement is described by Freud as "progrediant". Thus, the repressed will be able to appear without however appearing in the consciousness of the subject. These dreamlike manifestations then become the compromise between desires and defenses. The interpretation of the dream according to Freud is based on three elements, namely: the free association which is made by the patient, that is to say the manifest content of his dream as he tells it; the emotions and feelings associated with it, that is to say that which the dreamer presents during his narration; the interpretative associations that the psychoanalyst makes, that is to say the hidden meaning of the dream that the psychoanalyst is trying to decipher [10].

\section{The dream at Adler}

Adler, one of Freud's main disciples, was among the first to break away from the Freudian conception of psychic functioning. There were many discrepancies between this student and his teacher $[7,14,17]$ and among them, the conception of the dream and the source of the development of the personality. While for Freud [14], libido is the essence of personality development, Adler, on the other hand, leans towards the will to power, which he explains by the inferiority complex [11]. Regarding the dream, Adler thinks he is looking to the future and expresses the realization of a desire for power. He states that dreams, whether night or day, "accompany the desire to foresee, they arise when man is busy making his way to the future and walking there confidently" [12: P.47]. The author insists more on the imaginary and creative power of the dream. This will lead to the rupture between these two men in $1911[13,14]$.

\section{The dream at Jung's}

For Jung [14], the dream is a natural phenomenon which has the function of balancing and enriching the conscious. As for the unconscious, it is at the origin of the specific behaviors which we find within each species and which it calls "archetypes", and, this same unconscious is at the origin of the individual psychic, which 'he calls' individuation'. Jung created the concept of "complex" in 1908, developed the concept of "collective unconscious" which he explained through these archetypes, and then founded depth psychology or complex psychology. For Jung, the dream has several functions including the maintenance of the subject with its past, psychic individualization, prophecy or premonition. Jung [15] says, "Dreams are natural to me, which has no deceptive intentions and says what it has to say as well as it can - like a growing plant or an animal who seeks his pasture". This shows the position of the author in relation to the "dream work" that Freud constructed. For him, the dream is not intended to deceive or divert the subject from his desires, but is there, "To safeguard mental stability and even physiological health, it is necessary that consciousness and the unconscious are integrally connected, in order to "evolve in parallel. If they are cut from each other or dissociated, it results in psychological disorders. In this regard, the symbols of our dreams are the essential messengers who transmit information from the instinctive part to the part rationality of the human mind. Their interpretation enriches the poverty of consciousness, so that it learns to understand again the forgotten language of instincts" [14: P.41]. in a position which is opposed to that of Jung, Freud already affirmed that: "I have never seen anything, moreover, which confirms the prophetic value of a dream" [9: P.29].

\section{Physiological theories}

These are theories which explain the dream by physiological variations. These are the hypotheses of neurobiologists, the main ones of which are as follows.

\section{Theory of Roffwarg, Muzio and Dement}

For Roffwarg, Muzio and Dement [16], the dream plays a nonspecific role in cortical balance and, during ontogenesis, it serves as an endogenous stimulator. Thus, REM sleep would have the role of maintaining the functioning of systems that have not been stimulated during the prenatal and postnatal periods, like the visual system. 
The synthesis activation theory: Hobson and McCarley

This theory contrasts with the Freudian dream theory that it is the unconsciously suppressed desires that are responsible for the production of dreams. First developed by Hobson and McCarley in 1977, then matured by Hobson between 1988 and 1990, the theory of synthetic activation centers its reflections on the minimum threshold of physiological stimulations necessary for good brain functioning [17]. It stipulates that it is the nerve impulses produced by the neurons of the brainstem, precisely by the metencephalon (annular protuberance and the cerebellum), which is at the origin of dreams. For Purves., et al. [6], citing Lindsey, these cerebral regions which intervene during the daytime phase in the control of posture, balance, gaze and eye movements, also activate during sleep period, sending thus signals to the cortex, in order to maintain it at a threshold level of arousal. Thus, attempts by the cortex to process and synthesize these signals are thought to be at the origin of the production of dreams. For these authors, dreams have no psychological significance [17]. Hobson (1988) states that the brain is always looking for the senses of brain stimulation and variation, even when they have none. However, the author insists that the study of these meanings invented by the cortex can allow the individual to better understand "his own perceptions, conflicts and concerns, not by trying to dig under his dreams, as the advocates Freud, but by examining the surface itself" [17: P.96].

\section{The monoaminergic theory}

The neurological mechanism that produces the dream is not exactly known. However, it would seem that three monoamine keys intervene successively in the production of the dream [16]. It's about:

- First the serotonergic key: The serotonergic neurons seem to be involved in the construction, at the level of the raphe of the Varole bridge, of the conditions necessary for the triggering of the dream. This stage constitutes the preparatory phase of the dream.

- Then, the cholinergic key: observations have shown that anticholinergic drugs like atropine can suppress dreaming while acetylcholine agonists like serine can increase their production under certain conditions. This phase also takes place at the Varole Bridge.

- Finally, the catecholaminergic key: During this phase called the executive phase of the dream, the catecholamines (not necessarily norepinephrine) of the locus subcoeruleus would activate and would be at the origin of the phasic phenomena of REM sleep.

Assumptions of genetic reprogramming and psychic individualization

These are the theories that focus on the environment-gene interaction, that is to say, the fixation of learning in the genome of the individual, a process that could be described as genetic conservation of learning.
In 1988, Challamel and other French researchers found that newborn babies displayed facial expressions such as joy, fear, disgust, surprise, anger, sadness during REM sleep [7]. Thus, REM sleep would have the role of allowing the infant to learn behaviors which he will be called upon to produce in the future.

Jouvet [18] puts forward the hypothesis of relaying neurogenesis. He states "Dreams would be moments of genetic reprogramming of the individual, which would keep the synaptic circuits responsible for his psychological inheritance, the one responsible for his idiosyncratic reactions, functional" [18: P.162]. In other words, the dream would allow the brain to create its own identity, in order to withstand environmental pressures. For him, these environmental pressures tend to repress the genetic specificities of the individual and, paradoxical sleep meanwhile, has the function of allowing their expressions, by associating them with the personal experiences of the subject. It should be noted that this aspect of sleep, that is to say REM sleep, was discovered by Jouvet in 1959.

\section{Psychological and neuropsychological theories}

Psychological theories are those that attribute a psychological or psychophysiological cause or function to dreams. These are the most dominant scientific theories. They focus, among other things, on problem solving (cognitive theories), learning (memory theories) and finally, on individualizing genetic programming. However, several of these theories explain the first two psychological aspects.

\section{Cognitive and affective theories}

These theories view REM sleep or dreaming as a "repair shop" [7: P. 526]. These include among others the assumptions of: For Bergson 1901, Quoted by Lefranc [19], who dreams is only the consequence of the perception that the sleeper continues to develop during sleep. For him, the waking state and that of sleep have the same operating principles and on this, the dream comes on the one hand from real perceptions coming from the cerebral processing of sensory stimuli received by the organism during sleep [19].

Foulkes 1971, Quoted by Godefroid [7], notes that distressing dreams, whether in adults or children, are proportional to the difficulties the subject encounters during the waking state. In other words, dreams are just a reflection of daily activities and cognitions.

Hartmann 1973, Quoted by [7] shows that certain subjects feel better when they have dreams in which several characters intervene in it, and remember more agonizing dreams than dreams with weak emotional expressions. From this analysis, we can see two dream functions, namely, a memory function characterized by the positive influence of emotions in memory consolidation, and a cathartic function. This last function is that which allows the dreamer to solve some of his socio-emotional problems.

Concerning the affective approach, Cartwright 1977, Quoted by Godefroid [7] puts forward the hypothesis according to which several subjects remember their dreams more when these were preceded by a day of tension or depression, than when those These are preceded by a calm and peaceful day. Then, Webb and Cartwright 
1978, Quoted by Godefroid [7], add that dreams would offer the sleeper the possibilities of resolving the emotional conflicts that arose during the waking period. For this approach, the dream would allow the dreamer to resolve the emotional difficulties he encountered during previous waking periods.

For Nielsen., et al. [20], dreams would reduce the negative connotations of disturbing or traumatic events, reactivating them in another context.

In short, "REM sleep would thus provide the individual with the opportunity to partially resolve their problems, as well as to restore their own self-esteem" [7: P.526].

\section{Memory theories}

Fueled by advances in learning neuropsychology, these theories are centered on the role of REM sleep in general and that of dreams in particular, in the process of processing, organizing and maintaining information in memory. This is what is called cognitive information processing in cognitive psychology. They include the following assumptions.

\section{The "active unlearning" hypothesis}

It was developed by Crick and Mitchison and states that the dreams produced during REM sleep have the function of breaking the neural connections established by mistake, and those therefore once established, are not used in a significant way [6,17]. It emphasizes the ordering in the brain, of information received during the day by the subject, by removing parasitic information and by fixing the relevant information, this would protect the subject from obsessions and fantasies which could follow from it, following memory overload [7].

\section{The hippocampal consolidation hypothesis}

For Winson and several other researchers, REM sleep allows the information received by the subject to be consolidated in the hippocampus [7]. In other words, dreams would allow information to go from short-term memory to long-term memory. The author puts forward the idea that learning before sleep is better memorized for a longer period of time than learning just after waking up. Similarly, Bloch., et al. [7], found that after intense learning, the duration of REM sleep was increased by 30 to $60 \%$.

\section{The theory of virtual threat simulation}

Referring to the evolutionary approach advocating the disappearance of useful functions and the unique conservation of useful functions, he advances the hypothesis according to which dreams would help to react in a suitable and effective manner to dangerous situations in real life [20]. Developed by Revonsuo [21], it suggests that negative dreams are useful for the human species, and play the role of "a virtual night training, safe in bed, to be able to face all kinds of dangers" [22: P.63]. This theory considers that bad dreams are the norm and play an adaptive role, while good dreams are rather exceptions. The results of a study carried out by Arnulf and coll. on the dreams of students on the eve of a medical school entrance examination, corroborate this theory by showing that the vast majority of these students had bad dreams and nightmares related to exam failure, whether on the side of those who passed the exam or on the side of those who failed. This study calls into question the premonitory function of dreams and, foresees another, "that which consists in staging situations in an anticipatory manner" [22: P.64].

Some studies on the relationship between dreams and physiological activities

The dream has a central and important place in the birth of scientific psychology, because some of the pioneers of scientific psychology such as Vaschide and Pieron [23], undertook an experimental study on dreams, aimed at showing the close relationship between our somatic dreams and diseases. They collected by the experimental method 13 dreams in volunteers under observation, having preceded the somatic diseases, which occurred in these subjects a few days after the dream. The remarkable results of this study show that the part of the body involved in the dream is also that where the symptom appears a few days later [23]. At the end of the study, they hypothesized that certain dreams could be the expression of stimuli from physiological activities, so that some of them could help in the diagnosis of pathologies. In connection with this research, Manouvrier [23] affirms that "dreams of this kind can certainly provide semiological indications which it would be wrong to overlook". Thus, Vaschide [23], in the conclusion of this experimental study, states that "I only wanted to report definite relationships between certain dreams and inflammatory conditions from the semiological point of view, dreams that we were able to observe with H. Pedestrian during our dream research". Dement [24] has shown that the rapid eye movements observed in the sleeper during REM sleep are synchronized with the direction of the dreamer's gaze in his dream. Research on narcoleptic patient's states that their breathing variations in REM sleep reflect their dreamlike mental content [25]. Another [1], shows in a study that the relationship that the sleeper has with his dreams can cause physiological disorders such as high blood pressure, diabetes, or even cancer. These disturbances would settle in two ways, namely, the neurovegetative pathway via the intense solicitations of certain organs and physiological systems during REM sleep, and the post-dreamlike or daytime pathway involving the psychic processes developed by the subject upon waking (process which are partly a function of his level of education), the cultural beliefs and practices to which the dream material is subjected for interpretation, as well as the reaction of those close to the dreamer. These psychological factors indexed here are the dreamer's level of vulnerability to stress, his cultural beliefs and convictions, and his level of education. Social factors, for their part, are the reaction and involvement of the dreamer's entourage in the face of their dreams (dream interpretations), and the norms and values of their culture of belonging.

\section{Materials and Methods}

Sampling, tools, data collection and analysis techniques

Participants were randomly selected from the pulmonology, ENT, gastroenterology, and stomatology departments at a regional 
hospital in Yaoundé. To test the research hypotheses, 20 questionnaires of a mixed or semi-open nature (quantitative responses and qualitative responses) were given in each department (80 in total), 70 questionnaires were completed and collected, or 15 in pneumology, 20 in ENT, 19 in gastroenterology, and 16 in stomatology. In other words, 35 patients with problems related to the respiratory system, and 35 patients with problems related to the digestive system. For the quantitative responses, the participants were asked, through the items, to give an estimate ranging from $0 / 10$ (no symptoms) to $10 / 10$ (severe symptoms) of the intensity of the main symptoms of the physiological system involved in their suffering and another subscale asked them to estimate from $0 / 10$ to $10 / 10$ the frequency of dreams related to breathing and digestion. For the qualitative responses, patients were asked to answer yes or no if they ever had meal dreams and/or choking dreams. Qualitative data was organized and analyzed in terms of frequency, and quantitative data was organized and analyzed by the Pearson correlation method.

Alternative hypotheses (Ha) and null hypotheses (Ho)

- Hr1: Patients with respiratory problems would have more dreams in which the respiratory system is stressed than those who do not.

- Ha1: The frequency of dreams of suffocation is higher in patients with respiratory problems than in those who do not (unilateral hypothesis).

- Ho1: The frequency of dreams of suffocation is the same in patients with respiratory problems as in those who do not.

- Hr2: Patients with digestive problems have more dreams in which the digestive system is affected than those who do not.

- Ha2: The frequency of meal dreaming is higher in patients with digestive problems than in those who do not (unilateral hypothesis).

- Ho2: The frequency with which meal dreams occur is the same in patients with digestive problems as in those who do not.

- Hr3: There is a link between the somatic symptoms experienced by the patient and the manifest content of his dreams.

- Ha: $\rho \neq 0$, the intensity of the link between the somatic symptoms experienced by the patient and the manifest content of his dreams is statistically non-zero (bilateral hypothesis)

- Ho: $\rho=0$, the intensity of the link between the somatic symptoms experienced by the patient and the manifest content of his dreams is statistically zero.

\section{Results, Interpretation and Discussion}

Results of qualitative data

At the start of the data organization, we very quickly found that the responses from the ENT department and those from the pulmonology department were almost identical, the same for the responses from the stomatology department and that of the gastroenterology department. This led us to group them according to this new organization, which still respects the basic operationalization which separates respiratory and digestive disorders. We have ENT and pulmonology which refer to the respiratory system, stomatology and gastroenterology which refer to the digestive system:

- $23 / 35$ (or $65.71 \%$ ) of patients in the gastroenterology and stomatology departments claim to have more or less dreams of meals or consumption (with an average estimate score of 6.5/10) since the onset of their symptoms, compared to only $16 \%$ of ENT and pulmonology patients.

- $26 / 35$ (or $74.2 \%$ ) of patients in the pulmonology and ENT departments claim to have more or less dreams of suffocation or drowning (with an average score of 5.9/10), compared to only $11 \%$ of patients in the gastroenterology and stomatology departments.

Results of quantitative data

\begin{tabular}{|l|c|c|}
\hline \multicolumn{1}{|c|}{ Parameters } & Description & Value \\
\hline $\mathrm{N}$ & Sample & 70 \\
\hline $\mathrm{df}$ & Degree of freedom & 68 \\
\hline $\boldsymbol{\alpha}_{/ 2}$ (bilateral hypothesis) & Margin of error & $\begin{array}{c}0,05 / 2= \\
0,025\end{array}$ \\
\hline $\mathrm{r}_{\text {read }}$ & $\begin{array}{c}\text { Pearson correlation } \\
\text { read } \mathrm{r}_{(\alpha 2)}\end{array}$ & $+0,23$ \\
\hline $\mathrm{r}_{\text {cal }}$ & $\begin{array}{c}\text { Calculated Pearson } \\
\text { Correlation }\end{array}$ & $+0,64$ \\
\hline
\end{tabular}

Table

Linear regression line from $\mathrm{X}$ to $\mathrm{Y}: \mathrm{Y}(\mathrm{x}), \mathrm{Y}=0.83 \mathrm{X}+0.27$.

With: $\mathrm{X}$ the intensity of the somatic symptoms experienced by the patient, and $Y$ the frequency of the appearance of dreams, the manifest content of which solicits the dysfunctional somatic system.

Interpretation and Discussion

In view of the data collected on the sample, $65.71 \%$ of patients in the gastroenterology and stomatology departments claim to have more or less dreams of meals or consumption since the onset of their symptoms, compared with only $16 \%$ of ENT patients and pulmonology who claim to have this type of dream; $74.2 \%$ of patients in the pulmonology and ENT departments say they have more or less dreams of suffocation or drowning, compared to only $11 \%$ of patients in the gastroenterology and stomatology departments. Despite the empirical relevance of these figures, we do not find it necessary to analyze them by a hypothesis test relating to proportions or distributions, since for qualitative responses of YES or NO type, it would take a large sample line to hope have reliable results. A sample of 70, although a large sample from a statistical point of view, is considered very small for a survey of this type. 
However, if we limit ourselves to these data, we can see that the hypotheses Hr1 and Hr2 prove to be very relevant. We cannot say that they are confirmed, since they have not been tested by a hypothesis test, but their relevance is obvious.

With $r_{\text {cal }}(0.64)>r_{\text {lu }}=(0.21)$, the hypothesis Ho, stating that the intensity of the link between the somatic symptoms experienced by the patient and the manifest content of his dreams is statistically zero is rejected. Its rejection systematically implies acceptance of the Ha hypothesis, which states that the intensity of the link between the somatic symptoms experienced by the patient and the manifest content of his dreams is statistically non-zero. From these results, it is possible with $5 \%$ restraint that there is a link between the somatic symptoms felt by the patient and the manifest content of his dreams. This link can be envisaged in the form of a dependency link in which the somatic symptoms influence the manifest dreamlike content of the patient. This dependent linearity could be estimated from the following regression line: $\mathrm{Y}(\mathrm{x})=0.83 \mathrm{X}+$ 0.27 . It makes it possible to predict the frequency of the appearance of dreams in relation to a dysfunctional physiological system, depending on the intensity of the somatic symptoms experienced by the patient. From the perspective of the theory of synthetic activation, it would seem that the sensory stimuli induced by somatic dysfunction would be transmitted to the hypothalamus. This in turn would relay them to the cerebral cortex. The latter would try to give meaning to these nerve impulses, by trying to remain objective despite the altered state of consciousness.

This corroborates the hypothesis of the anticipatory function of dreams, put forward by Grosliere., et al. [25] or the virtual simulation theory advanced by Revonsuo and Valli [21]. This same function has been implied by Vaschide and Pieron since 1901, in an experimental study. But unlike the studies of Grosliere and col, and those of Revonsuo and Valli which test threats of a psychological nature, here the threat is physical, as in the studies of Vaschide and Pieron [23].

\section{Conclusion}

The present study, showing that there is a significant linear correlation between the intensity of the somatic symptoms felt by the patient and the frequency of the appearance of dreams, the manifest content of which solicits the dysfunctional physiological system, shows at the same time that the stimulations sensory received by the organism can induce or modify the quality of the sleeper's dream. Patients with digestive system disorders have more dreams of eating and drinking, while those with respiratory problems have more dreams of suffocation and/or drowning. The regression line of $\mathrm{Y}$ as a function of $\mathrm{X}$, with $\mathrm{Y}$ the frequency of appearance of a type of dream, and $X$ the intensity of the physical disorder, makes it possible to predict the dysfunctional physiological system according to the frequent dream content. This correlation seems more correct in patients whose symptoms are still in an acute stage and are more frequent during the incubation period of the disease. This new knowledge allows us to question the interpretations made by most cultures in the world, about digestive dreams which are generally perceived as signs of mystical imprisonment, perpetrated by a sorcerer or an evil spirit [26]. What if those dreams were just signs of a latent digestive disorder, when you don't have a particular symptom? If this is the case, it is time to consider a new interpretation of dreams, which will be guided by a psychophysical look. The construction of a biomedical dream interpretation model would facilitate both the early diagnosis of certain pathologies, and the targeting of certain systems in patients whose data collected so far do not facilitate the formulation of a diagnostic impression.

\section{Acknowledgements}

We thank the French and French-speaking research society in sleep medicine which, by setting up the sleep congress, motivated the setting up of this research work, and which allowed us to present it at the sleep congress in Lille 2018 by the identifier P.129.

\section{Conflict of Interest}

No conflict of interest.

\section{Bibliography}

1. Mbangmou RS and Ketcha Wanda GJM. "Oneiric Manifestations and Psychophysiological Dynamics: When the Dream Facilitates the Installation of Psychosomatic Disorders". EC of Psychology and Psychiatry 8.8 (2019): 813-829.

2. Jouvet M. “Evolution des états de sommeil”. Conférence $N^{\circ} 35$ ”. Université de tous les savoirs, France (2000).

3. Nielson Toré. “Entretien sur le rêve avec”. Mbangmou R. S. Entretien, Mail (2015).

4. Gay M. "Bien dormir, source d'énergie. Sous les ailles du sommeil”. Paris: Dervy (1999).

5. Montangéro J. “Rêve et cognition”. Sprimont: Mardaga (1999).

6. Purves D., et al. "Neurosciences". (JM Coquery, trad.). Paris: De Boeck University (1999).

7. Godefroid J. "Psychologie, science humaine et cognitive". Bruxelles: De Boeck. $3^{\text {rd }}$ édition (2011).

8. Kurth H. "Dictionnaire des rêves de A à Z". Paris: Club France Loisir (1977).

9. Freud S. "Cinq leçons de psychanalyse". (Y Le Lay, Trad.). Paris: Payot (2003).

10. Freud S. "L'interprétation du rêve". (J-P Lefebvre, trad.). Paris: Seuil. (Ouvrage original publié en 1900 sous le titre Die Traumdeutung) (2010).

11. Adler A. "Pratique et théorie de la psychologie individuelle compare". Paris: Payot (1961). 
12. Adler A. "Connaissance de la vie, Étude de caractérologie individuelle". Paris: Payot (1966).

13. Miquel J. "Cours de philosophie. Exposés et documents". Paris: Roudil $5^{\text {th }}$ édition (1982).

14. Crabbé JM. "Relations entre rêves et maladies” (2010).

15. Trigano P and Vincent A. "Le sel des rêves". Une refondation de la psychothérapie par une lecture nouvelle de C. G. Jung. Paris: Dervi (2004).

16. Jouvet M. "Le sommeil et le rêve”. Paris: Odile Jacob (1992).

17. Tavris C and Wade C. "Introduction à la psychologie. Les grandes perspectives“. Québec: Erpi $2^{\text {nd }}$ édition. (2007).

18. Jouvet M. "Programmation génétique itérative et sommeil paradoxal”. Confrontations Psychiatriques 27 (1986): 153-181.

19. Lefranc J. "Profil d'un auteur: Freud” (1996).

20. Sterpenich V and Schwartz S. "Nos émotions sous l'influence des rêves”. Mensuel 454 (2011).

21. Revonsuo A and Valli K. "Dreaming and consciousness: Testing the threat simulation theory of the function of dreaming". Psyche 6 (2000): 1-31.

22. Arnulf I. "Une fenêtre sur les rêves, neurologie et pathologie du sommeil". Paris: Odile Jacob (2014).

23. Vaschide $\mathrm{N}$ and Piéron $\mathrm{H}$. "Contribution à la séméiologie du rêve". Bulletins de la société d'anthropologie de Paris 5.2 (1901): 293-300.

24. Dement WC. "Dormir, rêver". Paris: Seuil (1981).

25. Grosliere L., et al. "Will you pass a competition that you previously failed in your dreams?" Consciousness and Cognition (2014).

26. Mbangmou RS and Nguimfack L. "Culture, rêve, et travail de psychisation de la maladie chez le patient atteint de cancer: une psychosomatique ethnopsychanalytique?" Revue Française de Psycho-Oncologie 14.1 (2020).

\section{Assets from publication with us}

- Prompt Acknowledgement after receiving the article

- Thorough Double blinded peer review

- Rapid Publication

- Issue of Publication Certificate

- High visibility of your Published work

Website: https://www.actascientific.com/

Submit Article: https://www.actascientific.com/submission.php Email us: editor@actascientific.com

Contact us: +919182824667 